\title{
Structure Change of Polyethersulfone Hollow Fiber Membrane Modified with Pluronic F127, Polyvinylpyrrolidone, and Tetronic 1307
}

\author{
Nasrul Arahman ${ }^{1 *}$, Bastian Arifin ${ }^{1}$, Sri Mulyati ${ }^{1,2}$, Yoshikage Ohmukai' ${ }^{2}$, Hideto Matsuyama ${ }^{2}$ \\ ${ }^{1}$ Department of Chemical Engineering, Syiah Kuala University, Banda Aceh, Indonesia; ${ }^{2}$ Department of Chemical Science and Engi- \\ neering, Kobe University, Kobe, Japan. \\ Email: ${ }^{*}$ nasrular@unsyiah.ac.id
}

Received October $9^{\text {th }}, 2011$; revised January $21^{\text {st }}, 2012$; accepted February $5^{\text {th }}, 2012$

\begin{abstract}
Hydrophilic polyethersulfone (PES) hollow fiber membranes were prepared via non-solvent induced phase separation (NIPS) by addition of polymeric additives as a membrane modifying agent. The effect of the addition of hydrophilic surfactant Pluronic F127, Polyivinylpyrrolidone (PVP), and Tetronic 1307 on the performance of the final PES hollow-fiber membrane was investigated. The morphology of fabricated hollow fiber membrane observed by scanning electron microscopy (SEM) indicated that all of membrane had a skin layer on the surface and finger like macrovoid structure inside the hollow fiber. The addition of $5 \mathrm{wt} \%$ polymeric surfactant on the polymer solution results in membrane with improved length and number of macrovoid structure. Sponge formation both near inner surface and near outer surface of hollow fiber membrane was another impact of addition of polymeric additives, which is led to decrease of water permeability of these membrane. Water contact angle measurement was performed to investigate the hydrophilicity property of resulted membrane. It is confirmed that the modified PES hollow fiber membranes had lower water contact angle than that of the original membrane, which indicate that the modified PES membrane with additives has high hydrophilic.
\end{abstract}

Keywords: Membrane Preparation; Polyethersulfone; Tetronic 1307; Pluronic F127; Polyivinylpyrrolidone

\section{Introduction}

Ultrafiltration (UF) as a novel separation technology has been widely applied in water purification process for the removal of particles, turbidity, microorganism, and natural organic matter (NOM) from surface water and groundwater [1-3]. These method offers several advantages such as consistent high quality of water, capable of removing a wide range of substances, and fewer addition of chemicals to raw water in treatment process $[2,4]$. The UF technology was established with large plants installed worldwide since 1980 [5]. This membrane rapidly expanding due to the need for purifying drinking water. The researchers are now developing high performance of UF membrane module for drinking water treatment. Membranes were fabricated and modified with various methods [6-8]. The purpose is to obtain high performance of UF membrane with high flux, high rejection, high fouling resistance, good chemical resistant and mechanical stability.

Porous polymeric membrane can be fabricated by se-

"Corresponding author. veral methods, including sintering, stretching, track etching, and phase separation processes [9]. The obtained membrane structures and properties can be controlled based on material properties and the preparation condition. Most of commercially available membranes are prepared by phase separation method which can be induced in four main techniques for the preparation of polymeric membranes [10]. Those are methods of thermally induced phase separation (TIPS), air-casting of the polymer solution, precipitation from vapor phase, and non-solvent induced phase separation (NIPS) or immersion precipitation. This paper mainly focuses on preparation and modification of poly(ether sulfone) hollow fiber membrane via NIPS process. In the membrane preparation process via NIPS, a polymer is dissolved in the solvent at room temperature, and homogeneous polymer solution is casted on a support or is extruded through a spinneret and subsequently immersed in a non-solvent coagulant bath to solidify the membrane. Phase separation occurs due to the inflow of non-solvent to the casting solution [11-13]. The separation performance depends on properties of the resulted membrane, such as degree of hydrophilicity, pore 
size and pore distribution, surface charge, and membrane thickness. The hydrophilicity, porosity, and skin layer thickness of membrane can be modified by addition of additive to the casting solution such as polyvinyl pyrrolidone (PVP), polyethylene glycol (PEG), Pluronic, etc. This method is known as a membrane modification process. In general, the objectives for modification of membrane morphology is to improve fouling resistance. Thus, the membrane life time can be longer than unmodified membrane.

Modification of polyethersulfone membrane morphology by addition of PVP at various molecular weight and concentration has been investigated intensively [14-16]. Addition of PVP into PES-DMF (dimethylformamide) contributes to increasing of membrane hydrophilicity. Thus, this additive could act as fouling preventing agent [14]. Increasing of permeability without significant change in selectivity by addition of small quantities of PVP was also observed by Ochoa, N.A and co-workers [15]. The research group of Wang succeeded in making a hydrophilic PES flat membrane by adding surfactant Pluronic F127 into the polymer solution [18-20]. The presence of Pluronic F127 in blend membrane could improve fouling resistance of the resulting membrane. In our previous study [21], surfactant Tetronic 1307 was used as a membrane modifying agent in order to improve the membrane performance. The permeability decline of the PES blend membrane with Tetronic 1307 in BSA filtration was lower than that of the original PES membrane because of its greater hydrophilicity. In the present study, the Pluronic F127, PVP, and Tetronic 1307 were used as membrane modifying agent to produce high performance of PES hollow fiber membrane. The effects of those additives on the performance, characteristics, and fouling property of the fabricated membranes are systematically compared.

\section{Experimental}

\subsection{Material}

PES (Ultrason E6020 P) with $\mathrm{M}_{\mathrm{w}}$ 65,000 was purchased from BASF Co. N-Methyl-2-Pyrrolidone (NMP) was obtained from WAKO (Pure Chemical Industries, Ltd, Japan). Surfactant Tetronic 1307, and Pluronic F127 were purchased from BASF Co. Polyvinil pyrrolidone (PVP K30), was purchased from SIGMA (Germany). Dextran with molecular weight of 77,000 obtained from SIGMA ALDRICH (Germany) was used as agent for solute rejection investigation. All such chemicals were used without further purification. The water used was high-quality deionized water (DI water, $>15 \mathrm{M} \Omega \cdot \mathrm{cm}^{-1}$ ) produced by an Elix-5 system (Millipore).

\subsection{Preparation of Hollow Fiber Membrane}

Hollow fiber membrane was prepared via non-solvent in- duced phase separation (NIPS) by a batch-extruder using a similar method applied in our previous work [22]. Dope solutions were prepared by dissolved $20 \mathrm{wt} \%$ of PES and $5 \mathrm{wt} \%$ of additives in NMP (Table 1). The homogenous polymer solution were obtained by stirring the solution at $300 \mathrm{rpm}$ for 24 hours. The dope solutions were left in the reservoir for 4 hour to allow complete release of bubbles.

All of membrane preparation conditions were maintained to be similar, as shown in Table 2. The hollow fiber was extruded from the spinneret and wound on a take-up winder after entering into the coagulation batch to induce phase separation, and solidify the membrane. The polymer flow rate through spinneret was controlled by a gear pump. Water as inner coagulation media was flow into inner tube to make lumen of the hollow fiber. The prepared hollow fiber membranes were kept in the pure water before testing.

\subsection{Membrane Morphology}

Membrane morphologies (surface and cross section) were observed by a Scanning Electron Microscope (SEM, Hitachi Co., JSM-5610LVS, Japan) with an accelerating voltage of $15 \mathrm{kV}$. The hollow fiber membranes were freeze-dried using a freeze dryer (EYELA, FD-1000, Japan) at temperature of $-40^{\circ} \mathrm{C}$ for 24 hours. For cross section observation, the freeze-dried membranes was fractured in liquid nitrogen.

Table 1. Dope polymer composition.

\begin{tabular}{llll}
\hline Membrane & PES (wt\%) & NMP (wt\%) & Additives (wt \%) \\
\hline 1 & 20 & 80 & - \\
2 & 20 & 75 & Pluronic F127 (5) \\
3 & 20 & 75 & PVPK30 (5) \\
4 & 20 & 75 & Tetronic 1307 (5) \\
\hline
\end{tabular}

Table 2. Preparation condition of PES hollow fiber membrane.

\begin{tabular}{ll}
\hline Spinneret dimension $(\mathrm{mm})$ & OD/ID $=1.00 / 0.70$ \\
\hline Polymer flow rate $(\mathrm{m} / \mathrm{min})$ & 3.10 \\
Inner coagulant & Water \\
Inner coagulant flow rate $(\mathrm{m} / \mathrm{min})$ & 13.0 \\
Take-up speed winder $(\mathrm{m} / \mathrm{min})$ & 13.6 \\
Air gap distance $(\mathrm{cm})$ & 10.0 \\
Bath composition & $100 \%$ water \\
Temperature $\left({ }^{\circ} \mathrm{C}\right)$ & 25 \\
\hline
\end{tabular}




\subsection{Membrane Hydrophilicity}

The hydrophilicity properties of the hollow fiber membrane were observed by measuring water contact angle of the outer surface of membrane at room temperature by a contact angle meter (Kyowa Interface Science Co., Drop Master 3000, Japan). A $0.5 \mu$ l of de-ionized water was dropped on the outer surface of hollow fiber membrane using microsyringe with a stainless stel needle and the contact angle was recorded automatically. Each sample was randomly measured for 20 times and an average value was calculated as the contact angle of that membrane. The time between the deposition of a droplet in the membrane surface and the measurement of the contact angle was kept as short as possible in order to avoid a change of droplet volume due to water evaporation or absorption.

\subsection{Water Permeability and Solute Rejection Test}

Both experiments were carried out by using a cross flow filtration system. The schematic diagram of laboratoryscale apparatus by using the single hollow fiber module used for the experiments are shown in Figure 1. For water permeability observation, deionized water was forced to permeate from the inside to the outside of the hollow fiber membrane by peristaltic pump. The transmembrane pressure could be applied by adjusting the pressure valve close to the release side, and the average of the readings of the two pressure gauges of $0.05 \mathrm{MPa}$ was taken as the filtration pressure. The solute rejection experiment was performed by using solution contained $1 \mathrm{wt} \%$ dextran with molecular weight of 77,000 . The solute rejection $(R)$ of membrane was obtained by measuring the concentration of dextran in feed and permeate by using UV spectrophotometer (GE-Healthcare) at $254 \mathrm{~nm}$ of wave length. Rejection of dextran calculated by the following equation:

$$
\text { Rejection }[\%]=\left(\frac{C_{0}-C}{C_{0}}\right) \times 100
$$

where $C_{0}$ and $C$ are the concentration of humic acid in feed and permeate, respectively.

The fluxes of deionized water and dextran solution was collected every 10 minutes and calculated on the basis of the inner surface area of the hollow fiber membrane.

\section{Results and Discussion}

\subsection{Membrane Morphology}

In order to understand the effect of membrane modifying agent on the structures of the PES membrane, the crosssection and surface structure of all fabricated membranes were observed by SEM. Surface structures of PES mem- brane with and without additives are shown in Figure 2. It is shown that, all of membranes had porous structures with rough surface. The structure change between PES original membrane and PES blend membrane was not so clear because the pores were too small formed on the surface.

Figure 3 shows the SEM image of whole cross-section and enlarged cross-section of membrane prepared by PES/ NMP system and the membrane prepared by PES/NMP/ Pluronic F127, PES/NMP/PVP, and PES/NMP/Tetronic 1307 system. In all cases, fingerlike macrovoids were clearly formed inside the hollow fiber membranes. Addition of membrane modifying agent in the polymer solution brought about the increase of number and length of fingerlike structure. Sponge area in the center path of hollow fiber membrane prepared by PES/NMP system was also disappear when the membrane modifying agent added. Figure 4 shows the structure of membrane near the inner

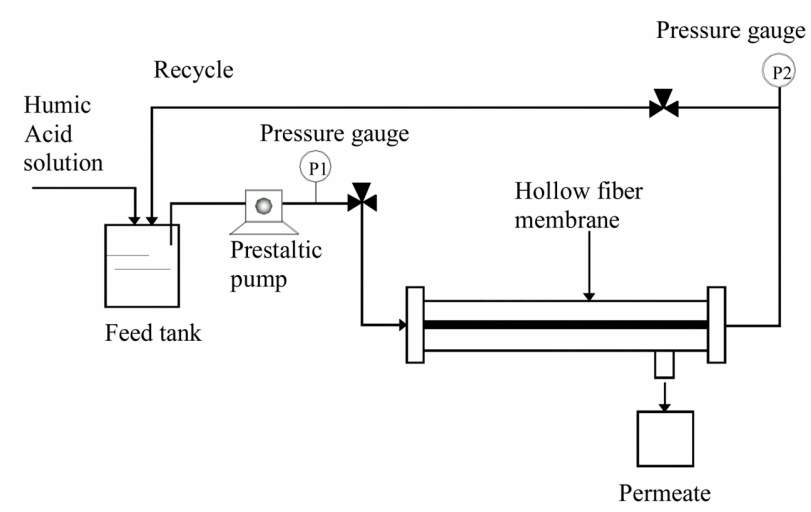

Figure 1. Schematic diagram of single hollow fiber membrane module employed in fouling experiment.

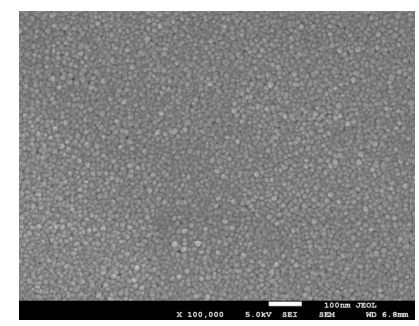

(a) PES

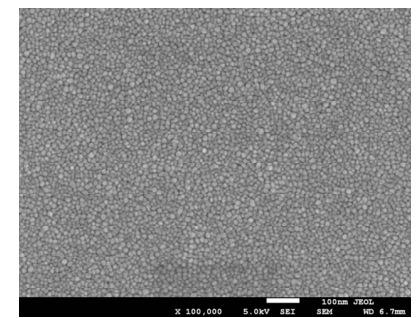

(c) PES/PVP

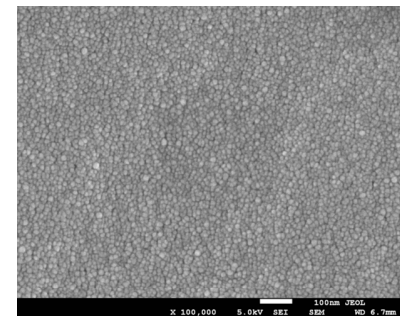

(b) PES/F127

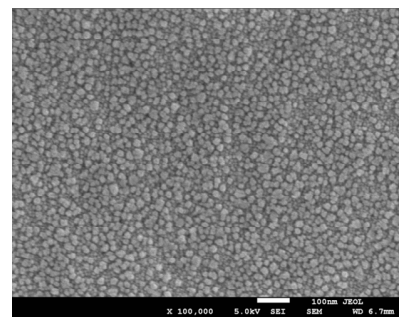

(d) PES/T-1307
Figure 2. SEM images of the outer surface of PES hollow fiber membrane with and without additive. 

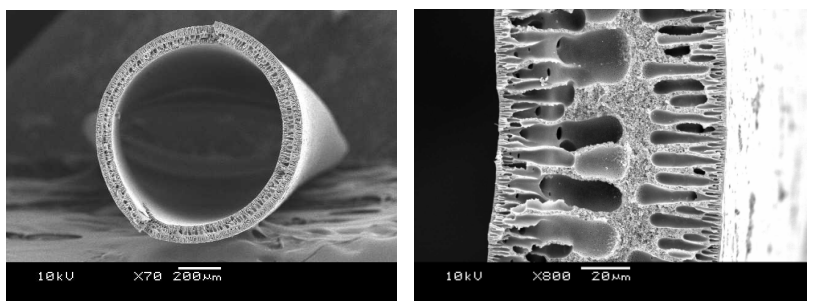

(a) PES
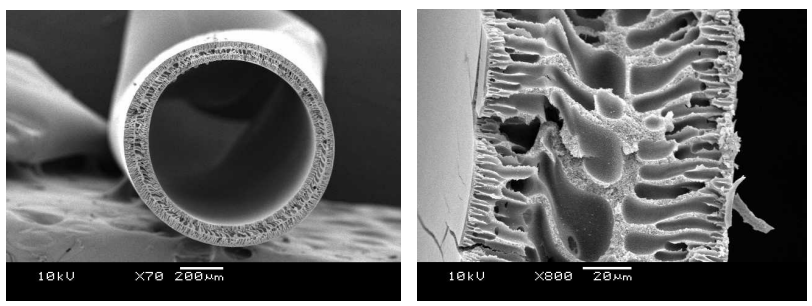

(c) PES/PVP
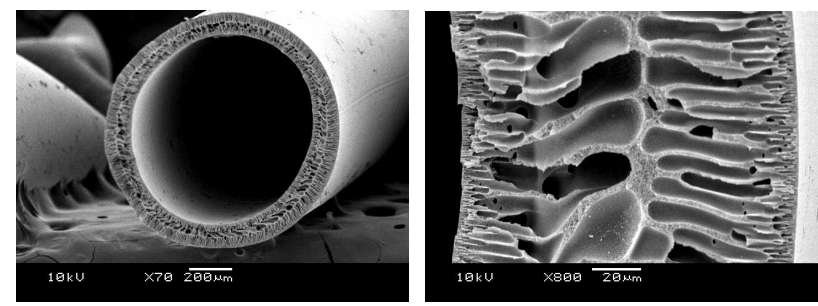

(b) PES/F127
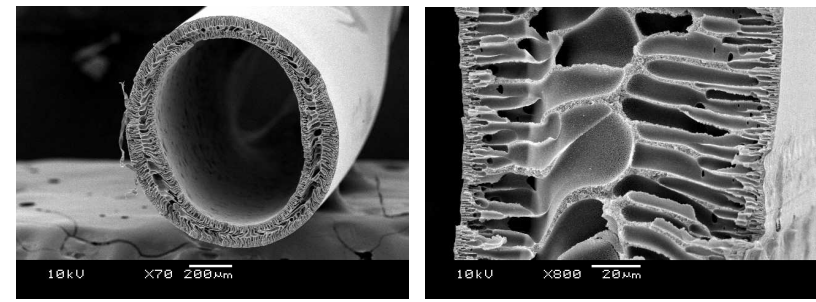

(d) PES/T-1307

Figure 3. Structure change of PES hollow fiber membrane observed by SEM. Left: whole cross-section; right: enlarged cross-section.
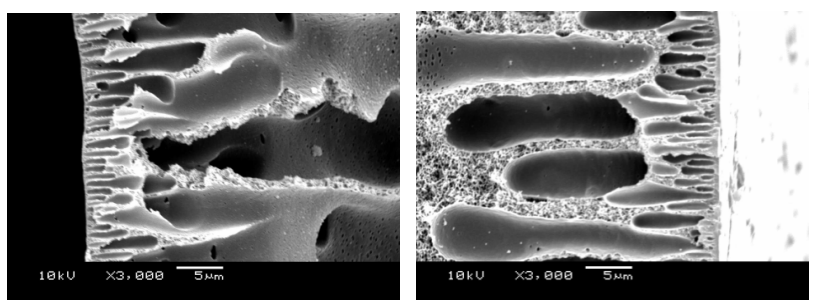

(a) PES
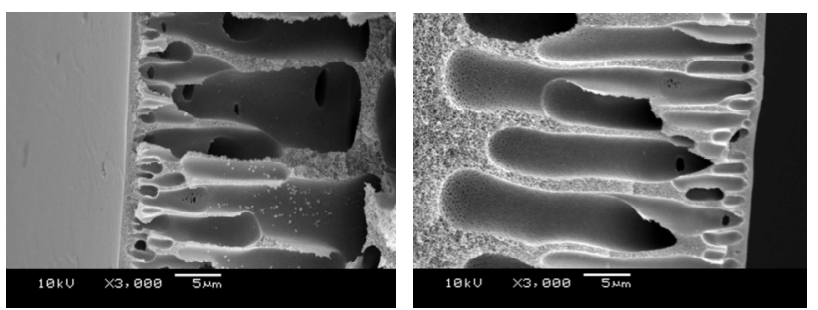

(c) PES/PVP
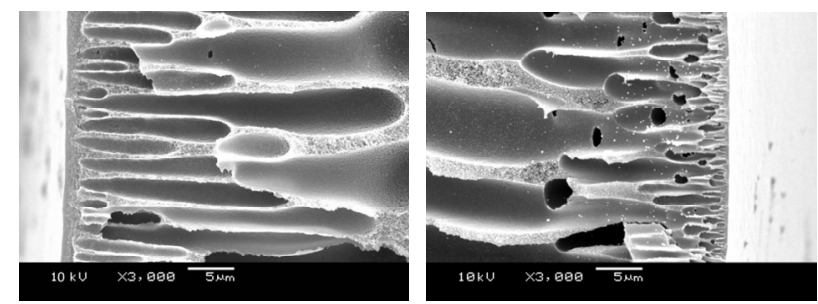

(b) PES/F127
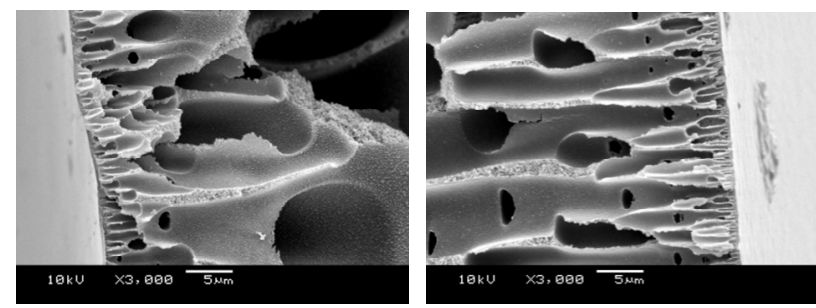

(d) PES/T-1307

Figure 4. SEM images of PES hollow fiber membranes with and without additive. Left: near inner surface; right: near outer surface.

and the outer surface of all resulted membrane. An increased of fingerlike structure was clearly observed by addition of additive as membrane modifying agent. In the membrane preparation via non-solvent induced phase separation process, the addition of the third component in the polymer solution brought about the decrease in the non-solvent amount that is necessary to obtain phase separation [22]. This means, the phase separation easily occurs by the addition of polymeric additive as a third component in the dope solution, that results membrane with enhanced growth of macrovoid inside the hollow fiber membrane. On the other hand, addition of $5 \mathrm{wt} \%$ of Pluronic F127, PVP, and Tetronic 1307 led to the formation of a sponge layer near the inner and outer surface, as shown in Figures 4(b)-(d). The existence of hydrophilic additives on the surface of PES hollow fiber membrane may result in formation of sponge layer on the inner and the outer surface of membrane.

\subsection{Membrane Hydrophilicity}

PES membranes have excellent chemical resistance, wide range temperature in application, and desirable mechanical strength. This polymer is widely used in membrane preparation for various applications [23-25]. However, their antifouling property is poor, which is the main disadvantage of this polymer in practical application. In this work, hydrophilic polymer was added to the polymer so- 
lution in order to improve the hydrophilicity property of PES membrane. Three types of polymeric additives were blended to PES system. The hydrophilicty of blend membrane was observed by water contact angle measurement. The results are presented in Table 3. The original PES membrane prepared from PES/NMP system showed the higher water contact angle, which indicate the membrane is hydrophobic. In all cases, water contact angle decreased when the polymeric surfactant added to the polymer solution. This means, the membrane became more hydrophilic.

\subsection{Filtration Performances}

Table 4 also lists the ultrafiltration performance of the series of hollow fiber membrane. The water permeability of PES original membrane is higher than that of the others membrane blended with additives. Addition of $5 \mathrm{wt} \%$ of polymeric additives into this polymer system lead to the formation of sponge layer near both the inner and the outer surface of PES hollow fiber membrane (Figure 3). This is the reason for decreasing of water permeability of PES/F127, PES/PVP, and PES/T1307 membranes. The rejection of $1 \mathrm{wt} \%$ dextran (Average $\mathrm{MW}=77.000)$ is higher than $90 \%$ in all membrane system.

\section{Conclusion}

Polyethersulfone (PES) hollow fiber membrane was prepared via non-solvent induced phase separation process, and the effect of addition of three different polymeric additives, i.e., pluronic F127, PVP, and Tetronic 1307 on the characteristic and performances of fabricated membranes was investigated. SEM investigation showed that the increase macrovoid structure inside the hollow fiber membrane by the addition of all polymeric additives. Sponge formation both near inner surface and near outer surface of hollow fiber membrane was the another impact of addition of polymeric additives, which led to decrease of water permeability of these membrane. The hydrophilicity of all modified membrane analyzed by water con-

Table 3. Hydrophilicity property of membrane observed by water contact angle measurement.

\begin{tabular}{cccc}
\hline & $\begin{array}{c}\text { Water } \\
\text { Membrane System } \\
\text { Contact Angle } \\
\left(^{\circ}\right)\end{array}$ & $\begin{array}{c}\text { Water } \\
\text { Permeability } \\
\left(\mathrm{L} / \mathrm{m}^{2} \cdot \mathrm{h} \cdot \mathrm{atm}\right)\end{array}$ & $\begin{array}{c}\text { Solute } \\
\text { Rejection } \\
(\%)\end{array}$ \\
\hline PES & 71.6 & 88.65 & 92.60 \\
PES/F127 & 63.2 & 72.15 & 93.99 \\
PES/PVP & 60.85 & 66.72 & 94.43 \\
PES/T-1307 & 61.75 & 20.80 & 96.80 \\
\hline
\end{tabular}

tact angle was higher than that of the original PES membrane, which indicate the additives are exist on the surface of hollow fiber membrane.

\section{Acknowledgements}

We would like to thank the Directorate General of Higher Education, The Ministery of National Education, Indonesia for the financial support of this work.

\section{REFERENCES}

[1] J. H. Green and M. Tylla, "A Comparison of Ultrafiltration on Various River Waters," Desalination, Vol. 119, No. 1-3, 1998, pp. 79-84. doi:10.1016/S0011-9164(98)00114-3

[2] X. Guo, Z. Zhang, L. Fang and L. Su, "Study on Ultrafiltration for Surface Water by a Polyvinylchloride Hollow Fiber Membrane," Desalination, Vol. 238, No. 1-3, 2009, pp. 183-191. doi:10.1016/j.desal.2007.11.064

[3] S. J. Xia, X. Li, J. Yao, B. Z. Dong and J. J. Yao, “Application of Membrane Techniques to Produce Drinking Water in China," Desalination, Vol. 222, No. 1-3, 2008, pp. 497-501. doi:10.1016/j.desal.2007.01.142

[4] S. Nakatsuka, I. Nakate and T. Miyano, "Drinking Water Treatment by Using Ultrafiltration Hollow Fiber Membranes," Desalination, Vol. 106, 1996, pp. 55-61.

[5] R. W. Baker, "Membrane Technology and Applications," John Wiley \& Sons, Hoboken, 2004. doi: $10.1002 / 0470020393$

[6] S. S. Madaeni, M. Falsafi and N. Ghaemi, "A Novel Method for Preparation of Low-Fouling Membranes: Surface Coating by Extracted Wax from Leafy Cabbage," Desalination, Vol. 283, 2011, pp. 148-155. doi:10.1016/j.desal.2011.03.050

[7] D. Wandera, S. R. Wickramasinghe and S. M. Husson, "Modification and Characterization of Ultrafiltration Membranes for Treatment of Produced Water," Journal of Membrane Science, Vol. 373, No. 1-2, 2011, pp. 178188. doi:10.1016/j.memsci.2011.03.010

[8] C. H. Loh, R. Wang, L. Shi and A. G. Fane, "Fabrication of High Performance Polyethersulfone UF Hollow Fiber Membranes Using Amphiphilic Pluronic Block Copolymers as Pore-Forming Additives," Journal of Membrane Science, Vol. 380, No. 1-2, 2011, pp. 114-123. doi:10.1016/j.memsci.2011.06.041

[9] M. Mulder, "Basic Principles of Membrane Technology," 2nd Edition, Kluwer Academic Publishers, London, 1996. doi:10.1007/978-94-009-1766-8

[10] P. van de Witte, P. J. Dijkstra, J. W. A. van den Berg and J. Feijen, "Phase Separation Processes in Polymer Solutions in Relation to Membrane Formation," Journal of Membrane Science, Vol. 117, No. 1-2, 1996, pp. 1-31. doi:10.1016/0376-7388(96)00088-9

[11] H. Matsuyama, K. Nakagawa, T. Maki and M. Teramoto, "Studies on Phase Separation Rate in Porous Polyimide Membrane Formation by Immersion Precipitation," 
Journal of Applied Polymer Science, Vol. 90, No. 1, 2003, pp. 292-296. doi:10.1002/app.12783

[12] A. Rahimpour and S. S. Madaeni, "Improvement of Performance and Surface Properties of Nano-Porous Polyethersulfone (PES) Membrane Using Hydrophilic Monomers as Additives in the Casting Solution," Journal of Membrane Science, Vol. 360, No. 1-2, 2010, pp. 371-379. doi:10.1016/j.memsci.2010.05.036

[13] X. Fu, H. Matsuyama and H. Nagai, "Structure Control of Asymmetric Poly(Vinyl Butyral)- $\mathrm{TiO}_{2}$ Composite Membrane Prepared by Nonsolvent Induced Phase Separation," Journal of Applied Polymer Science, Vol. 108, No. 2, 2008, pp. 713-723. doi:10.1002/app.27711

[14] J. Marchese, M. Ponce, N. A. Ochoa, P. Prádanos, L. Palacio and A. Hernández, "Fouling Behaviour of Polyethersulfone UF Membranes Made with Different PVP," Journal of Membrane Science, Vol. 211, No. 1, 2003, pp. 1-11. doi:10.1016/S0376-7388(02)00260-0

[15] N. A. Ochoa, P. Prádanos, L. Palacio, C. Pagliero, J. Marchese and A. Hernández, "Pore Size Distributions Based on AFM Imaging and Retention of Multidisperse Polymer Solutes Characterisation of Polyethersulfone UF Membranes with Dopes Containing Different PVP," Journal of Membrane Science, Vol. 187, No. 1-2, 2001, pp. 227-237. doi:10.1016/S0376-7388(01)00348-9

[16] Y. Wang and B. Shi, "Concentration of Gelatin Solution with Polyethersulfone Ultrafiltration Membranes," Food and Bioproducts Processing, Vol. 89, No. 3, 2011, pp. 163-169. doi:10.1016/j.fbp.2010.06.004

[17] B. Chakrabarty, A. K. Ghoshal and M. K. Purkait, "Preparation, Characterization and Performance Studies of Polysulfone Membranes Using PVP as an Additive," Journal of Membrane Science, Vol. 315, No. 1-2, 2008, pp. 36-47. doi:10.1016/j.memsci.2008.02.027

[18] Y. Q. Wang, Y. L. Su, Q. Sun, X. L. Ma and Z. Y. Jiang, "Generation of Anti-Biofouling Ultrafiltration Membrane Surface by Blending Novel Branched Amphiphilic Polymers with Polyethersulfone," Journal of Membrane Science, Vol. 286, No. 1-2, 2006, pp. 228-236. doi:10.1016/j.memsci.2006.09.040

[19] Y. Wang, Y. Su, Q. Sun, X. Ma and Z. Jiang, "Improved Permeation Performance of Pluronic F127-Polyethersulfone Blend Ultrafiltration Membranes," Journal of Membrane Science, Vol. 282, No. 1-2, 2006, pp. 44-51. doi:10.1016/j.memsci.2006.05.005

[20] Y. Q. Wang, T. Wang, Y. L. Su, F. B. Peng, H. Wu and Z. Y. Jiang, "Remarkable Reduction of Irreversible Fouling and Improvement of the Permeation Properties of Poly (Ether Sulfone) Ultrafiltration Membranes by Blending with Pluronic F127," Langmuir, Vol. 21, No. 25, 2005, pp. 11856-11862. doi:10.1021/la052052d

[21] N. Arahman, T. Maruyama, T. Sotani and H. Matsuyama, "Fouling Reduction of a Poly(Ether Sulfone) HollowFiber Membrane with a Hydrophilic Surfactant Prepared via Non-Solvent-Induced Phase Separation," Journal of Applied Polymer Science, Vol. 111, No. 3, 2009, pp. 1653-1658. doi:10.1002/app.29149

[22] N. Arahman, T. Sotani and H. Matsuyama, "Effect of the Addition of the Surfactant Tetronic 1307 on Poly(Ether Sulfone) Porous Hollow-Fiber Membrane Formation," Journal of Applied Polymer Science, Vol. 108, No. 5, 2008, pp. 3411-3418. doi:10.1002/app. 27940

[23] A. Rahimpour, S. S. Madaeni and Y. Mansourpanah, "The Effect of Anionic, Non-Ionic and Cationic Surfactants on Morphology and Performance of Polyethersulfone Ultrafiltration Membranes for Milk Concentration," Journal of Membrane Science, Vol. 296, No. 1-2, 2007, pp. 110-121. doi:10.1016/j.memsci.2007.03.029

[24] A. M. Sakinah, A. F. Ismaila, R. Md Illias and O. Hassan, "Fouling Characteristics and Autopsy of a PES Ultrafiltration Membrane in Cyclodextrins Separation," Desalination, Vol. 207, No. 1-3, 2007, pp. 227-242. doi:10.1016/j.desal.2006.08.007

[25] A. V. R. Reddy and H. R. Patel, "Chemically Treated Polyethersulfone/Polyacrylonitrile Blend Ultrafiltration Membranes for Better Fouling Resistance," Desalination, Vol. 221, No. 1-3, 2008, pp. 313-323. doi:10.1016/j.desal.2007.01.089 